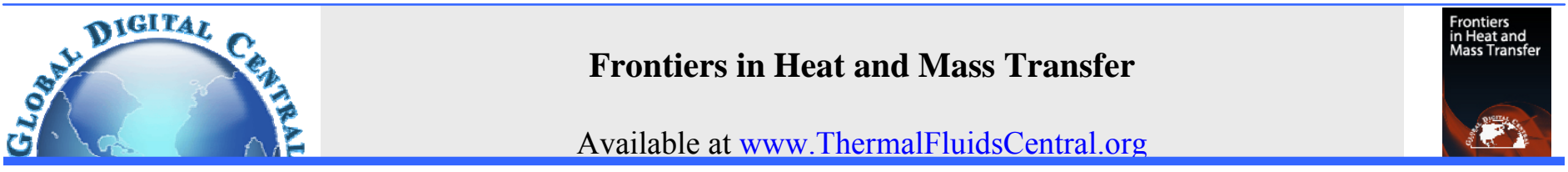

\title{
HEAT EXCHANGER DESIGN METHODOLOGY FOR ELECTRONIC HEAT SINKS
}

\author{
Ralph L. Webb \\ Department of Mechanical Engineering, Penn State University, University Park, PA 16802
}

\section{ABSTRACT}

This paper discusses the "Inlet Temperature Difference" (ITD) based heat-exchanger (and its variants) design methodology frequently used by designers of electronic heat sinks. The methodology is at variance with the accepted methodology recommended in standard heat-transfer text books - the "Log-Mean Temperature Difference" (LMTD), or the equivalent "effectiveness-NTU" design method. The purpose of this paper is to evaluate and discuss the ITD based design methodology and its deficiencies. The paper shows that the ITD based method is an approximation at best. Variants of the method can lead to either under or over prediction of the heat transfer rate. Its shortcomings are evaluated, and it is recommended that designers of electronic cooling equipment use the well established and accepted LMTD or $\varepsilon-N T U$ design methodology.

Keywords: ITD, LMTD, design method, heat-exchanger, thermal resistance

\section{INTRODUCTION}

Designers of electronic "heat sinks," using either air or water cooling, typically do not treat their device as a "heat-exchanger" and tend to tend to ignore traditional procedures and rules applicable to heatexchanger design. The key problem involved in the unconventional design of electronic cooling devices is that the designer bases the driving temperature difference on $\left(T_{h}-T_{7}\right)$, where $T_{h o t}$ is the hot source temperature and $T_{7}$ is the ambient (or inlet) coolant temperature. Such design methodology is described here as the "Inlet Temperature Difference" (ITD) design method. This is at variance with accepted design procedure for industrial, automotive, and air-conditioning heat exchangers, which use the "Log-Mean Temperature Difference" (LMTD), or the equivalent "effectiveness-NTU" ( $\varepsilon$-NTU) design method.

This difference in methodology to define the driving temperature difference raises questions concerning the application and validity either test or predicted results based on the ITD driving temperature difference method. Further, use of the ITD Method will lead to errors in predicted "heat sink" size, if the designer based the design on correlations for heat transfer coefficient that are either theoretically based, or obtained from experiment and reduced using the LMTD. The main thesis of this pape ${ }^{1} r$ is to show that what is described herein as the ITD design method is not a valid design method.

Before proceeding into the technical issues involved, it is helpful to understand:

1. Why the LMTD or the equivalent $\varepsilon-\mathrm{NTU}$ design method are used.

2. Conditions under which the ITD design method may be acceptable.

All undergraduate heat transfer text books [e.g., Incropera and DeWitt (2002)] present theoretical analysis of heat exchange between two streams, either for parallel or counter flow. The parallel flow analysis involves integrating the local driving temperature difference $\left(\mathrm{T}_{\mathrm{h}}-\mathrm{T}_{\mathrm{c}}\right)$ as a function of distance " $\mathrm{x}$ " along the flow direction. The local heat flux is calculated as

$d q=U\left(T_{h}-T_{c}\right) d A=U \cdot \Delta T \cdot d A$

The integration of Eq. 1 along the flow length yields

$\int_{1}^{2} \frac{d(\Delta T)}{\Delta T}=-U\left(\frac{1}{C_{h}}-\frac{1}{C_{c}}\right) \ln \left(\frac{\Delta T_{2}}{\Delta T_{1}}\right)$

Using $\mathrm{q}=\mathrm{C}_{\mathrm{h}}\left(\mathrm{T}_{\mathrm{h}, \mathrm{i}}-\mathrm{T}_{\mathrm{h}, \mathrm{o}}\right)$ and $\mathrm{q}=\mathrm{C}_{\mathrm{h}}\left(\mathrm{T}_{\mathrm{c}, \mathrm{i}}-\mathrm{T}_{\mathrm{c}, \mathrm{o}}\right)$, write Eq. 2 as

$q=U A\left[\frac{\Delta T_{2}-\Delta T_{1}}{\ln \left(\Delta T_{1} / \Delta T_{2}\right)}\right]$

The term in the square brackets on the right hand side of Eq. 3 is defined as the "Log-Mean Temperature Difference" (LMTD or $\Delta \mathrm{T}_{\mathrm{lm}}$ ). Hence, using this definition of $\Delta \mathrm{T}_{\mathrm{lm}}$ one would write Eq. 3 as

$q=U A \cdot \Delta T_{l m}$

The key point to understand in the derivation of Eq. 4 is that the appropriate driving temperature difference $\left(\Delta \mathrm{T}_{\mathrm{lm}}\right)$ accounts for the change of the driving temperature difference $\left(T_{h}-T_{c}\right)$ over the fluid flow length of the heat-exchanger. If the driving temperature difference had been defined as ITD $=T_{h}-T_{7}$, where $T_{7}=T_{c 1}$, this temperature difference would give a larger value the actual $\Delta \mathrm{T}_{\mathrm{lm}}$ defined by Eq. 3 and result in over-prediction of the heat transfer rate (q).

*Corresponding author. Email: Ralph.Webb@psu.edu 


\section{VALIDITY OF THE ITD DESIGN METHOD}

Use of the ITD as the driving temperature difference would give the same result as the LMTD method only if there was no temperature change of the fluid temperature along the flow length. Such would be the case if the heat is rejected to an infinite heat sink (e.g., of the heat sink temperature, which experienced no temperature change. This is typically assumed in "boundary layer flow" over an object for which the heat sink $\mathrm{T}_{7}$ is a constant. Figure 1a shows this case. However, for "channel flow" shown in Figure 1b, the heat sink fluid temperature changes along the flow length. The Figure $1 \mathrm{~b}$ situation is typically applied to heat exchanger design, where the fluid temperature changes along and Eq. 4 applies to this situation.

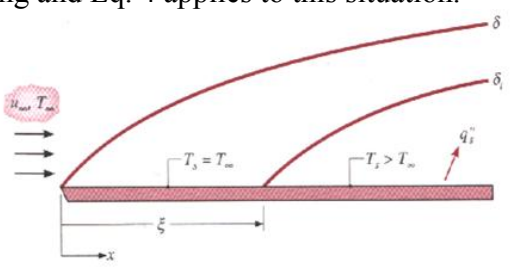

- Fluid heated in thin boundary layer.

- No bulk heating of fluid.

$$
\begin{aligned}
& q=h A\left(T_{w}-T_{\infty}\right) \\
& R_{c v}=\frac{1}{h A}=\frac{q}{I T D} \\
& I T D=T_{w}-T_{\infty}
\end{aligned}
$$

Fig. 1a: Boundary layer flow

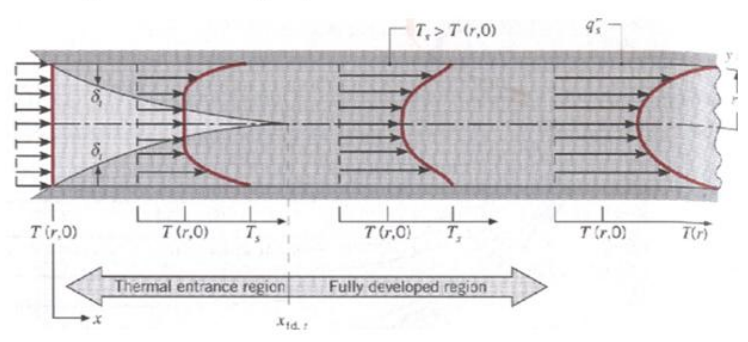

Bulk heating of fluid.

$$
\begin{aligned}
& q=h A \Delta T_{l m} \\
& R_{c v}=\frac{1}{h A}=\frac{q}{\Delta T_{l m}}
\end{aligned}
$$

Fig. 1b: Channel Flow

Fig. 1 a) Heat exchange in a) Boundary layer flow, where $T_{7}=$ constant, and b) For channel flow where the fluid temperature changes along the flow length (typical situation).

\section{THE LMTD (OR $\varepsilon$-NTU) DESIGN METHOD}

As shown in typical undergraduate heat transfer texts, one may calculate the heat transfer rate (q) using either the LMTD or $\varepsilon$-NTU design methods, which are equivalent methods. For the LMTD method, one would write

$$
q=F \cdot U A \Delta T_{1 m}
$$

where the flow configuration factor $\mathrm{F}=1$ for an electric heat input with a single coolant, which is typical of electronic cooling applications. Written in terms of thermal resistance, $\mathrm{R}_{\mathrm{tot}}=1 / \mathrm{UA}$, with $\mathrm{F}=1$, one may write Eq. 1 in the form

$R_{\text {tot }}=\Delta T_{1 m} / q$
The $\mathrm{R}_{\text {tot }}$ is defined as the sum of the thermal resistances in series between the heat source (or hot fluid) and the heat sink fluid. For example, consider a water-cooled micro-channel heat sink, which has three thermal resistances in series: interface resistance $\left(R_{\text {int }}\right)$, spreading resistance $\left(\mathrm{R}_{\mathrm{sp}}\right)$, and convection resistance $\left(\mathrm{R}_{\mathrm{cv}}\right)$. Thus,

$$
R_{\text {tot }}=R_{\text {int }}+R_{s p}+R_{c v}
$$

The $\mathrm{R}_{\mathrm{cv}}=1 / \mathrm{hA}$ and the $\mathrm{h}$-value is obtained from published solutions or correlations for the Nusselt number. If the heat is transferred between an electric heat input source at temperature $\mathrm{T}_{\text {hot }}$ and the coolant, whose inlet and outlet temperatures are $T_{c, \text { in }}$ and $T_{c, \text { out }}$, respectively, then the LMTD is based on these temperatures. The LMTD is defined as

$$
\Delta T_{1 m}=\frac{\left(T_{\text {hot }}-T_{c, \text { in }}\right)-\left(T_{\text {hot }}-T_{c, \text { out }}\right)}{\ln \left[\left(T_{\text {hot }}-T_{c, \text { in }}\right) /\left(T_{\text {hot }}-T_{c, \text { out }}\right)\right]}
$$

For the $\varepsilon$-NTU design method, one would write

$$
q=c_{\min } \varepsilon I T D
$$

where $\varepsilon=$ fcn $\left(\mathrm{C}_{\min } / \mathrm{C}_{\max }\right)$ and depends on the flow geometry. Further detail is given on the $\varepsilon$-NTU method in a later section.

\section{THE ITD DESIGN METHOD}

It is very common within the electronic cooling community to use a design method referred to here as the "ITD design method." This means that the driving temperature difference is based on $\mathrm{T}_{\text {hot }}-\mathrm{T}_{\mathrm{c}, \text { in }}(=\mathrm{ITD})$, where $T_{\text {hot }}$ is the hot source temperature and $T_{c, \text { in }}$ is the inlet coolant temperature and ITD is defined as the "Inlet Temperature Difference". Consider the case of electric heat input (q) from a heat source at temperature $\left(\mathrm{T}_{\text {hot }}\right)$ with hot base area $\mathrm{A}_{\text {hot }}$, rejecting heat to a coolant flowing in the micro-channel cooler having plan area $A_{p}$, as illustrated in Figure 2.

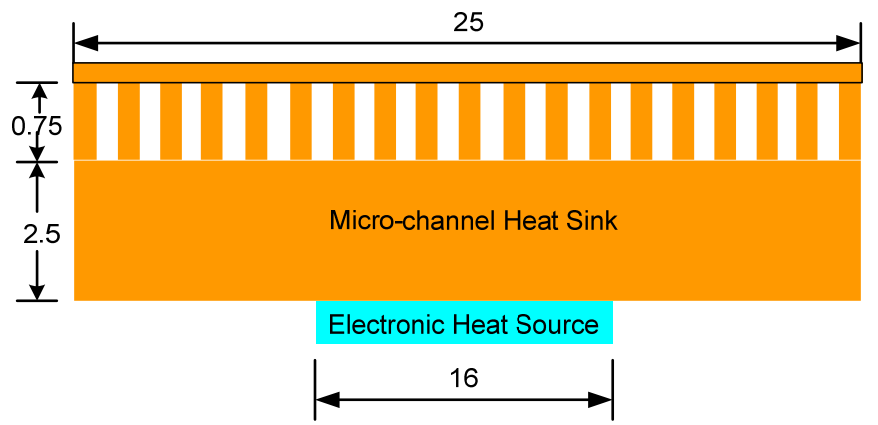

Fig. 2 Example electronic micro-channel heat sink with water-cooled channels.

When using the ITD design method, it is common for electronic heat sink designers to use one of several definitions given below for the "Overall Thermal Resistance."

\section{Definition 1}

$$
R_{\text {tot }, \text { ITD }}=\frac{T_{\text {hot }}-T_{c, \text { in }}}{q}=\frac{I T D}{q}
$$

By far, the most common definition found in the electronic cooling literature assumes that $\mathrm{R}_{\text {tot,ITD }}$ is given by Eq. 10 . The key deficiency and inaccuracy of this method is that the heat transfer rate (q) is insensitive to the fluid temperature rise (for constant $\mathrm{R}_{\text {tot,ITD }}$ ). This will result in over-prediction of the heat transfer rate when $R_{\text {tot,ITD }}$ is calculated from component thermal resistances as defined by Eq. 7 . 


\section{Definition 2}

Simons (2006) defines a thermal resistance to be added to Eq. 7 to account for the effect of the coolant rise on the driving temperature difference. The modified definition for $\mathrm{R}_{\text {tot,ITD }}$ is given by Eq. 11 .

$$
R_{\mathrm{tot}, I T D}=\frac{I T D}{q}=R_{\mathrm{tot}}+\frac{T_{c, \text { in }}-T_{c, \text { out }}}{2 q}=R_{\mathrm{tot}}+\frac{\Delta T_{c} / 2}{q}
$$

where $R_{\text {tot }}$ is the sum of the several thermal resistances between the heat source and coolant fluid (e.g., Eq. 2). The $\mathrm{R}_{\text {tot }}$ is given by Eq. $1 \mathrm{~b}$. The second term in Eq. 11 is defined as the "fluid thermal resistance" $\left(R_{\text {fluid }}\right)$

and is equal to $1 /\left(2 \mathrm{~m} \mathrm{c}_{\mathrm{p}}\right)$. By adding the $\mathrm{R}_{\text {fluid }}$ term, the calculated $\mathrm{q}$ is sensitive to the coolant rise. This approach is equivalent to defining an $R_{\text {tot }}$ based on driving temperature difference $\left(T_{\text {hot }}-T_{\text {ave }}\right)$, where $T_{\text {ave }}$ is the average fluid temperature difference. However, the result is not in exact agreement with that determined using the LMTD method. The author is not aware if the modified $\mathrm{R}_{\text {tot,ITD }}$ definition of Eq. 11 has been proposed earlier by another author.

\section{Definition 3}

A variant of Eq. 11 is given in a recent textbook on electronic cooling, Yeh and Chu (2002), as

$R_{\text {tot }, \text { ITD }}=\frac{I T D}{q}=R_{\text {tot }}+\frac{T_{c, \text { in }}-T_{C, \text { out }}}{q}=R_{\text {tot }}+\frac{\Delta T_{C}}{q}$

where $\mathrm{R}_{\text {tot }}$ has the same definition as that used for Eq. 11. However, the second term in Eq. 12 is defined as $R_{\text {fluid }}=\Delta T_{c} / q=1 /\left(\dot{m ~ c}_{p}\right)$ and is twice the value of $\mathrm{R}_{\text {fluid }}$ in Eq. 11. If $\mathrm{R}_{\text {tot }}$ is calculated from component thermal resistances (Eq. 7), this will result in prediction of a q-value less than that of the LMTD method.

\subsection{IMPLICATIONS OF THE ITD METHOD}

If one uses Eq. 10 to reduce test data, the calculated $R_{\text {tot,ITD }}$ will be higher than the $\mathrm{R}_{\text {tot }}$ based on use of Eq. 1b. Use of Eq. 11 will yield an $R_{\text {tot,ITD }}$ value that is closer to the $R_{\text {tot }}$ given by Eq. $1 b$.

Using Eq. 10, one would write as

$q=I T D / R_{t o t, I T D}$

Authors who use Eq. 10 assume that the defined $\mathrm{R}_{\text {tot,ITD }}$ is the sum of the several series thermal resistances between the hot source $\left(T_{\text {hot }}\right)$ and the entering coolant $\left(\mathrm{T}_{\mathrm{c}, \text { in }}\right)$ and that $\mathrm{R}_{\text {tot,ITD }}$ is also equal to $\mathrm{R}_{\text {tot }}$, as given by Eq. 7 .

If one seeks to predict $R_{\text {tot,ITD }}$ by calculating the component thermal resistances, they assume that the convection resistance $\left(R_{c v}\right)$ may be calculated as $1 / \eta \mathrm{hA}$, where the h-value is taken from published solutions or correlations. If one uses $\mathrm{R}_{\mathrm{cv}}=1 / \eta \mathrm{hA}$ and sets the summed component thermal resistances equal to $\mathrm{R}_{\text {tot,ITD }}$ the heat transfer rate (q) will be over-predicted, relative to the value predicted using Eq. $1 \mathrm{~b}$.

It is very rare to see use of either Eq. 11 or 12 in the electronic cooling literature. Predictions of q using summed component thermal resistances with the $5 \mathrm{~b}$ definition will yield a better definition of $\mathrm{q}$ than use of Eq. 10. This is because Eq. 11 defines the driving temperature as the arithmetic temperature difference, rather than the log-mean temperature difference. However, use of Eq. 10 will over-predict q.

This paper seeks to encourage adoption of the standard and accepted heat exchanger design methodology for the design of electronic cooling equipment. Example calculations are provided to show the differences, relative to the LMTD method, that result from use of the "ITD design method."

\section{COMPARISON OF DESIGN METHODS}

If Eq. 4 and 10 are both valid, they must predict the same $q$ for the same $\mathrm{R}_{\text {tot }}$ (as defined by Eq. 1b). Solving Eq. 4 and 10 for $\mathrm{q}$ and setting them equal, we obtain

$R_{\text {tot }, I T D}=\frac{I T D}{\Delta T_{1 m}} R_{t o t}=\frac{I T D}{\Delta T_{1 m}} \frac{1}{U A}$

Because ITD $>$ LMTD, $R_{\text {tot,ITD }} \geq 1 /$ UA. This means that it is not valid to define $\mathrm{R}_{\text {tot,ITD }}$ as the sum of the component thermal resistances (Eq. 7) for the Eq. 10 ITD design method. The only condition, for which the ITD design method can give a q-value equal to the LMTD method for single-phase flow is if ITD = LMTD. This will exist for only two cases: 1) If the coolant flow is infinite, which is an impractical situation, or 2) For a two-phase coolant, the fluid temperature is constant (neglecting the effect of two-phase pressure drop on the vapor temperature). However, if the two-phase fluid is convection cooled by a gas or liquid loop, an additional single-phase resistance will be involved and the $\mathrm{R}_{\text {tot,ITD }} \geq 1 / \mathrm{UA}$.

Note that the concept of a "fluid thermal resistance" $\left(\mathrm{R}_{\text {fluid }}\right)$ does not exist in the LMTD of $\varepsilon$-NTU design methods. If one uses the ITD

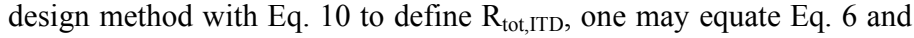
10 for $\mathrm{q}$ to show that the precise definition for the associated $\mathrm{R}_{\text {fluid }}$ is given by

$R_{\text {fluid }}=R_{\text {tot }}\left(\frac{I T D}{\Delta T_{1 m}}-1\right)$

If the designer insists on using the ITD driving temperature difference, one may use Eq. 15 to provide an accurate calculation of the $\mathrm{R}_{\text {fluid, }}$, which must be added to correctly define $\mathrm{R}_{\text {tot,ITD }}$ using $\mathrm{R}_{\text {tot }}$ from Eq. 7 .

\section{EXAMPLE PROBLEM 1}

An example problem has been prepared to illustrate the difference in results obtained by the ITD and LMTD design methods. The example involves a water-cooled micro-channel heat sink similar to that shown in Figure 2. The copper micro-channel heat sink is $25 \mathrm{~mm}$ wide and 20 $\mathrm{mm}$ flow depth with two water passes. The fins are $0.75 \mathrm{~mm}$ high and $0.24 \mathrm{~mm}$ thick, placed on $0.44 \mathrm{~mm}$ pitch. There are 28 fins in each of the two passes. It has an integrated heat spreader $2.5 \mathrm{~mm}$ thick, with the same base area as the micro-channel plate. It receives heat from a 16 $\mathrm{mm}$ square electrically heated source that is soldered to the heat sink, and which does not involve a thermal interface resistance. Water enters at $35^{\circ} \mathrm{C}$ and the hot source temperature is constrained to $70^{\circ} \mathrm{C}$. For simplicity the convection resistance is calculated using the Nusselt number for fully developed laminar flow with constant heat flux $(\mathrm{Nu}=$ 5.3) in a 0.25 aspect ratio channel, as given by Eq. 349 in Shah and London [1978]. The spreading resistance is calculated using the equation provided by Lee et al. [1995]. For laminar flow, the convection heat transfer coefficient is constant $\left(\mathrm{h}=9972 \mathrm{~W} / \mathrm{m}^{2}-\mathrm{K}\right.$, and is independent of water flow rate. The $\mathrm{R}_{\mathrm{cv}}=1 / \eta \mathrm{hA}=0.0467 \mathrm{~K} / \mathrm{W}$ and $\mathrm{R}_{\mathrm{sp}}=0.031 \mathrm{~K} / \mathrm{W}$, resulting in $\mathrm{R}_{\mathrm{tot}}=0.0777 \mathrm{~K} / \mathrm{W}\left(\mathrm{R}_{\mathrm{cv}}+\mathrm{R}_{\mathrm{sp}}\right)$. This example uses Eq. 7 to calculate the heat transfer rate (q) using the LMTD design method. The LMTD is based on $\mathrm{T}_{\text {hot }}, \mathrm{T}_{\mathrm{c}, \text { in }}$ and $\mathrm{T}_{\mathrm{c}, \mathrm{out}}$. An iterative calculation is necessary to calculate the LMTD, because the $\mathrm{T}_{\mathrm{c}, \text { out }}$ depends on q. Eq. 10, 11, and 12 have been used for the ITD design method. The same value of $\mathrm{R}_{\mathrm{tot}}$ is used for all design methods.

Table 1 shows the calculated heat transfer rate for different flow rates using the LMTD and various ITD design methods. The calculations were performed for water flow rates up to $20 \mathrm{~g} / \mathrm{s}$, for which the flow is in the laminar regime.

For the LMTD method, q increases with increasing water flow rate, because the LMTD increases with increasing water flow rate. Because the ITD is constant, the Eq. 10 ITD method gives $\mathrm{q}=450 \mathrm{~W}$ for all water flow rates. The q defined by Eq. 11 approximates the result of the LMTD method. Eq. 12 yields a q-value lower than that of the 
Table 1. Results for example problem $\left(35^{\circ} \mathrm{C}\right.$ water inlet temperature $)$.

\begin{tabular}{|c|c|c|c|c|c|c|c|}
\hline $\begin{array}{l}\text { Water } \\
\text { flow } \\
(\mathrm{g} / \mathrm{s})\end{array}$ & $\mathrm{Re}_{\mathrm{Dh}}$ & $\begin{array}{l}\mathrm{R}_{\mathrm{tot}} \\
1 / \mathrm{UA} \\
(\mathrm{K} / \mathrm{W})\end{array}$ & $\begin{array}{l}\Delta \mathrm{T}_{\mathrm{ln}} \\
(\mathrm{K})\end{array}$ & $\begin{array}{l}\mathrm{q}_{\text {LMTD }} \\
(\mathrm{W})\end{array}$ & $\begin{array}{l}\text { qITD } \\
\text { Eq. } \\
10 \\
\text { (W) }\end{array}$ & $\begin{array}{l}\mathrm{q}_{\mathrm{ITD}} \\
\text { Eq. } \\
11 \\
(\mathrm{~W})\end{array}$ & $\begin{array}{l}\mathrm{q}_{\mathrm{ITD}} \\
\text { Eq. } \\
12 \\
(\mathrm{~W})\end{array}$ \\
\hline 5 & 634 & 0.0777 & 26.21 & 337 & 450 & 344 & 238 \\
\hline 10 & 1152 & 0.0777 & 30.18 & 388 & 450 & 390 & 330 \\
\hline 15 & 1671 & 0.0777 & 31.67 & 408 & 450 & 408 & 366 \\
\hline 20 & 2190 & 0.0777 & 32.47 & 417 & 450 & 418 & 386 \\
\hline
\end{tabular}

LMTD method. Clearly, the Eq. 12 ITD design method (and the Eq. 11 and 12 variants) gives different results than those of the LMTD design method.

If a turbulent flow correlation were used for water flow rate $>20$ $\mathrm{g} / \mathrm{s}$, one would find that the LMTD would be further increased and higher values of $\mathrm{q}_{\mathrm{LMTD}}$ would be predicted. At infinite water flow rate, the LMTD = ITD and all three ITD methods would give the same $\mathrm{q}$.

The example problem clearly shows that if one defines $R_{\text {tot,ITD }}=R_{\text {tot }}$ (from Eq. 7) the Eq. 11 ITD method is insensitive to water flow rate and that the predicted results do not agree with those obtained by the LMTD method.

\section{EXAMPLE PROBLEM 2}

This problem involves simulated test data for a micro-channel heat sink using $35^{\circ} \mathrm{C}$ water inlet temperature and $200 \mathrm{~W}$ heat input. Laminar flow exists in the micro-channels, so the heat transfer coefficient (h) and $\mathrm{R}_{\mathrm{cv}}$ should be constant. As shown by Eq. 7, $\mathrm{R}_{\text {tot }}$ will be independent of flow rate. Hence, the LMTD should be constant, as shown by Eq. 8 .

The simulated test results are given in the first three columns of Table 2. The $\Delta \mathrm{T}_{\mathrm{c}}$ is obtained from a heat balance and the LMTD is calculated by Eq. 9. The tabled data are reduced to determine $\mathrm{R}_{\text {tot,ITD }}$ (using Eq. 11) and $\mathrm{R}_{\text {tot }}$ (from Eq. 7). The $\mathrm{R}_{\text {fluid }}$ term in Eq. 11 is

calculated as $\left(1 / 2 \mathrm{mc}_{\mathrm{p}}\right)$. The tabled results show that $R_{\text {tot }}$ is a constant. However, the $\mathrm{R}_{\text {tot,ITD }}$ decreases with increasing water flow rate, because the fluid temperature rise decreases. If the definition of $\mathrm{R}_{\text {fluid }}$ were exact, one would obtain $\mathrm{R}_{\text {tot,ITD }}-\mathrm{R}_{\text {fluid }}=\mathrm{R}_{\text {tot }}$, which is not the case. If one were to calculate $R_{\text {fluid }}$ from Eq. 8, one would find that $R_{\text {tot,ITD }}-$ $\mathrm{R}_{\text {fluid }}$ agrees with $\mathrm{R}_{\text {tot }}$ from the LMTD method. Although the definition of $R_{\text {fluid }}$ from Eq. 8 is exact, the process is cumbersome. The most straight-forward method is to directly apply the LMTD (or $\varepsilon$-NTU) design method.

A key purpose of this example is to show $\mathrm{R}_{\text {tot,ITD }}$ (Eq. 10) $\neq \mathrm{R}_{\text {tot }}$ (as given by Eq. 7. It also shows that when $\mathrm{R}_{\text {tot }}$ is calculated as $\mathrm{R}_{\text {tot,ITD }}$ -

$R_{\text {fluid }}$, where $R_{\text {fluid }}=1 /\left(2 \mathrm{~m} \mathrm{c}_{\mathrm{p}}\right)$, the resulting $R_{\text {tot }}$ is not equal to the $R_{\text {tot }}$ found by the LMTD design method. Hence, significant errors will exist if one attempts to predict q by the "ITD design method" using the Eq. 7 to obtain $\mathrm{R}_{\text {tot }}$. The error will be larger using Eq. 10, which does not account for the fluid temperature change.

Table 2. Results for Example Problem 2.

\begin{tabular}{llllllll}
\hline $\begin{array}{l}\text { Water } \\
\text { flow } \\
(\mathrm{g} / \mathrm{s})\end{array}$ & $\begin{array}{l}\mathrm{Q} \\
(\mathrm{W})\end{array}$ & $\begin{array}{l}\mathrm{T}_{\mathrm{h}} \\
\left({ }^{\circ} \mathrm{C}\right)\end{array}$ & $\begin{array}{l}\Delta \mathrm{T}_{\text {fluid }} \\
(\mathrm{K})\end{array}$ & $\begin{array}{l}\Delta \mathrm{T}_{\text {ln }} \\
(\mathrm{K})\end{array}$ & $\begin{array}{l}\mathrm{R}_{\text {tot }} \\
(\mathrm{K} / \mathrm{W})\end{array}$ & $\begin{array}{l}\mathrm{R}_{\text {tot,ITD }} \\
(\mathrm{K} / \mathrm{W})\end{array}$ & $\begin{array}{l}\mathrm{R}_{\text {fluid }} \\
(\mathrm{K} / \mathrm{W})\end{array}$ \\
\hline 5 & 200 & 55.80 & 9.57 & 15.54 & 0.0777 & 0.1040 & 0.0263 \\
10 & 200 & 53.05 & 4.78 & 15.54 & 0.0777 & 0.0903 & 0.0126 \\
15 & 200 & 52.19 & 3.19 & 15.54 & 0.0777 & 0.0860 & 0.0083 \\
20 & 200 & 51.77 & 2.39 & 15.54 & 0.0777 & 0.0839 & 0.00615 \\
\hline
\end{tabular}

\section{DISCUSSION}

For completeness, the $\varepsilon$-NTU formulation is also presented and discussed. As given by Equation 11.23 of Incropera and DeWitt [1996], the $\varepsilon$-NTU design method gives

$q=C_{\min } \varepsilon I T D$

Eq. 9 may be re-written as

$$
\frac{I T D}{q}=\frac{1}{\varepsilon C_{\min }}
$$

Comparison of Eq. $9 \mathrm{~b}$ and Eq. 6 shows that the right-hand side of Eq. $9 \mathrm{~b}$ is not equal to $\mathrm{R}_{\text {tot }}$ as defined in Eq. 6. For an electric heat input with a single fluid, Equation 11.36 of Incropera and DeWitt [1996] shows that

$$
\varepsilon=1-\exp (N T U)
$$

For this case, $\mathrm{C}_{\min }=\dot{\mathrm{m}} \mathrm{c}_{\mathrm{p}}$ and NTU $=\mathrm{UA} / \dot{\mathrm{m}} \mathrm{c}_{\mathrm{p}}$. For constant heat flux input to the coolant, substitution of Eq. 10 in Eq. $9 \mathrm{~b}$ shows that the term ITD/q is given by

$$
\frac{I T D}{q}=\left(\frac{1}{1-e^{-N T U}}\right) \frac{1}{C_{\min }}
$$

where $\mathrm{C}_{\min }=\mathrm{mc}_{\mathrm{p}}$. Use of the $\varepsilon$-NTU is a more direct method of working Example Problem 1, because it does not require an iterative solution to calculate the LMTD. However, it gives the same answer as the LMTD method.

For heat transfer to a two-phase coolant, the several ITD design methods will give the same result as the LMTD or $\varepsilon$-NTU design methods, if one does not account for the effect of two-phase pressure drop on the fluid saturation temperature.

\section{CONCLUSIONS}

1. Several conflicting "ITD design methods" appear in the electronic cooling literature. These methods are inconsistent with the well accepted LMTD or $\varepsilon$-NTU design methods.

2. The ITD design method defined by Eq. 10 is invalid for cooling systems that contain at least one single-phase coolant thermal resistance. The problem occurs because the method does not correctly define the driving temperature difference.

3. The total thermal resistance $\left(\mathrm{R}_{\text {tot,ITD }}\right)$ defined by the ITD design method (Eq. 10) is greater than the $R_{\text {tot }}$ (Eq. 6) defined by the LMTD design method.

4. The Eq. 11 definition, which includes a "fluid thermal resistance" is approximately correct, but not exact. The "fluid thermal resistance" defined in Eq. 12 is too large and will result in prediction of q less than that of the LMTD method.

5. Although it is possible to define an exact value $\mathrm{R}_{\text {tot,ITD }}$ by use of Eq. 12, the process requires application of the LMTD design method and it is cumbersome.

6. The well accepted LMTD or $\varepsilon$-NTU design methods are totally applicable to design of electronic heat sinks. Their use is strongly recommended.

\section{NOMENCLATURE}

A

$\mathrm{C}$ $\mathrm{D}_{\mathrm{h}}$
Heat transfer surface, hot source area $\left(\mathrm{A}_{\text {hot }}\right)$

Capacity rate $\left(=\dot{\mathrm{m}} \mathrm{c}_{\mathrm{p}}\right) \cdot \mathrm{C}_{\min }$ (minimum), $\mathrm{C}_{\max }$ (maximum)

Fluid specific heat

Hydraulic diameter 
h Heat transfer coefficient

ITD Inlet Temperature Difference $\left(\mathrm{T}_{\mathrm{h}}-\mathrm{T}_{\mathrm{c}, \text { in }}\right)$

LMTD Log-mean temperature difference (Eq. 3). Also written as $\Delta \mathrm{T}_{\mathrm{lm}}$

m Mass flow rate

NTU Number of thermal units $\left(=\mathrm{UA} / \mathrm{C}_{\min }\right)$

q Heat transfer rate

$\mathrm{T}_{\mathrm{c}} \quad$ Coolant temperature.

$\mathrm{T}_{\mathrm{c}} \quad$ Coolant temperature (inlet, $\mathrm{T}_{\mathrm{c}, \text { in }}$ ), (outlet, $\mathrm{T}_{\mathrm{c}, \text { out }}$ )

$\mathrm{T}_{\text {hot }} \quad$ Hot source temperature

$\mathrm{R}_{\mathrm{cv}} \quad$ Convection thermal resistance $(=1 / \eta \mathrm{hA})$

$\mathrm{R}_{\text {fluid }} \quad 1 /\left(2 \mathrm{~m} \mathrm{c}_{\mathrm{p}}\right)$ in Eq. 11 and $1 /\left(\mathrm{m} \mathrm{c}_{\mathrm{p}}\right)$ in Eq. 12

$\mathrm{R}_{\text {tot }} \quad$ Defined as 1/UA, valid for LMTD design method

$\mathrm{R}_{\text {tot,ITD }}$ Defined by Eq. 10, 11, or 12 for ITD design method

$\mathrm{R}_{\mathrm{sp}} \quad$ Spreading thermal resistance

$\mathrm{Re} \quad$ Reynolds number, $\mathrm{Re}_{\mathrm{Dh}}$ (based on hydraulic diameter)

U Overall heat transfer coefficient

$\varepsilon \quad$ Heat exchanger thermal effectiveness

$\eta \quad$ Surface efficiency for finned surface

$\Delta \mathrm{T}_{\mathrm{c}} \quad \mathrm{T}_{\mathrm{c}, \text { out }}-\mathrm{T}_{\mathrm{c}, \text { in }}$

\section{REFERENCES}

Incropera, F.P. and DeWitt, D.P., 1996, Fundamentals of Heat and Mass Transfer, $4^{\text {th }}$ ed., John Wiley $\&$ Sons, New York.

Lee, S., Song, S., Au, V. and Moran, K.P., 1995, "Constriction/Spreading Resistance Model for Electronics Packaging," Proc., $4^{\text {th }}$ ASME/JSME Thermal Engineering Joint Conference, Vol. 4, pp. 199-206.

Shah, R.K., and London A.L., 1978 "Laminar Flow Forced Convection in Ducts", p. 205, Academic press.

Simons, R.E., 2006. "A Simple Thermal Resistance Model - Isoflux versus Isothermal,” Electronics Cooling, Vol. 12, No. 1, pp. 6-8.

Yeh, L-T. and R. C. Chu, 2002, "Thermal Management of Microelectronic Equipment: Heat Transfer Theory, Analysis Methods and Design Practices," ASME Press. 